duction. It is a pity that almost every example in the book is American, as this must limit the book's usefulness and appeal for readers outside the North American con. tinent. It is also a pity that the author has eschewed the text-book approach to such an extent that several notable omissions occur. For example, the relationship of dip and strike to one another could have been better explained with the use of line diagrams. Also no attempt is made to indicate the importance of the chemistry or mineralogy of magmas, or of the chemical relations between magmas.

The book is aimed at those who take "introductory courses in geology for non-majors". For anyone who wants an introductory book which will give him the "feel" of the subject, this is a good buy, and it will probably find its way on to the shelves of many school and college libraries.

angela Marshall

\section{REFRACTORY METALS}

Chemical Thermodynamics in Nonferrous Metallurgy

Vol. 3: Thermodynamics of Tungsten, Molybdenum, Titanium, Zirconium, Niobium and Tantalum and of their more Important Compounds. By Ya. I. Gerasimov, A. N. Krestovnikov and A. S. Shakhov. Translated from the Russian by R. Kondor. Edited by M. Gleiser. Pp. ix + 237. (Jerusalem: Israel Program for Scientific Translations; London: Oldbourne Press, 1965.) $70 s$.

\section{Alloys of Niobium}

By D. A. Prokoshkin and E. V. Vssil'eva. Edited by A. M. Samarin. Translated from the Russian by N. Kaner. Translation edited by Molly Gleiser. Pp. xiv +336 . (Jerusalem: Israel Program for Scientific Translations; London: Oldbourne Press, 1965.) 117s.

Analytical Chemistry of Zirconium and Hafnium By S. V. Elinson and K. I. Petrov. (Analytical Chemistry of Elements Series.) Translated from the Russian by N. Kaner. Edited by D. Slutzkin. Pp. $x+206$. (Jerusalem: Israel Program for Scientific Translations; London: Oldboume Press, 1965.) $81 s$.

THEse books are a welcome addition to the literature dealing with the properties of refractory metals. All three are of interest not only for the original Russian work they contain, but also because they provide, to varying degrees, an admirably condensed treatment of widely scattered material.

Volume 3 of Chemical Thermodynamics in Nonferrous Metallurgy is a critical discussion of the available thermodynamic data relating to the compounds of tungsten, molybdenum, titanium, zirconium, niobium and tantalum, a separate chapter being devoted to each element. The data are presented in 246 tables, which indicate the method of preparation and probable errors in determination, as well as the preferred values based on a critical assessment by the authors. At the end of each chapter there is a valuable section on the high temperature oxidation and reduction reactions of the compounds listed. This is a very useful reference book, which can be strongly recommended to research workers and lecturers in pure and applied sciences engaged in the fields of extractive metallurgy, materials science, corrosion, chemical engineering and physical metallurgy. The volume is well translated, and the material clearly presented.

Alloys of Niobium, originally published in 1964, is a highly specialized reference book, solely concerned with the physical, chemical and mechanical properties of binary and ternary alloys of niobium; there is only a fleeting reference to methods of preparation and fabrication. The treatment is essentially factual, as can be gauged from the 300 figures and 120 tables. The inclusion of much original Russian work makes possible a wider selection of data than in previous treatments of niobium alloys but, despite the inclusion of 600 references, western literature does not seem to have been covered completely. There are some notable omissions, such as the work of Powers and Doyle, which makes Chapter 2 somewhat out of date.

As the book will no doubt be used extensively by research workers in the refractory metal field, it is a pity that some literal translations of technical terms have not been edited, and replaced by standard metallurgical terminology. The use of terms such as "packing defect" instead of "lattice defect" and "yield stage" instead of "yield point" does not make for easy reading. Some references appear incomplete, and some are plainly in error; for instance the Journal of the Institute of Metals has been confused with the Journal of Metals on a number of occasions. The treatment of ternary alloys is, however, particularly useful, because previous books dealing with the overall properties and production of niobium have neces. sarily not had the space to deal with this aspect in great detail. In addition, this is the field to which original Russian work has made a great contribution in recent years.

There is an interesting chapter dealing with the current development of industrial alloys, and the potential of such alloys in relation to other refractory metals. This rela. tively short piece reflects the fact that the majority of the information so far accumulated can still only be handled empirically, and that the underlying theory of alloying bohaviour is still not understood. In such a situation, the wealth of information available in this book makes it an indispensable addition to the literature on the metallurgy of niobium.

The monograph dealing with the analytical chemistry of zirconium and hafnium is part of a series intended to cover the available methods of analysis for all the elements. Some 800 references are listed in the bibliography, of which approximately a third are to Russian works. As the text is less than 200 pages, it follows that. although the necessary underlying principles are admirably presented in all cases, it will be necessary to make reference to the original work for complete details. Exhaustive, if condensed, deseriptions of many analytical methods are indeed given in many cases, and it is surprising how much information has been packed into this relatively small volume. Separate chapters deal with the separation of zirconium and hafnium from other elements, and their gravimetric, titrimetric, photometric and spectroscopic determination. Polarographic, radiometric, kinetic and activation methods, although listed in the index as a separate chapter, are covered in only five pages. Other chapters deal with the general chemical behaviour of these elements, and with the determination of impurities in zirconium and hafnium.

There is no doubt that the authors have performed a very valuable and useful service by bringing together so much information into one small volume, and, together with the other monographs in this series, the book will surely become a standard reference text in this field.

\section{A. P. MroDownik}

\section{MODERN ANALYSIS}

\section{Analytical Chemistry}

(Progress in Nuclear Energy Series IX.) Vol. 6. Edited by D. C. Stewart and H. A. Elion. Pp. v + 260. (London and New York: Pergamon Press, Ltd., 1966.) 90s, net.

THIs is the ninth book in the Progress in Nuelear Energy Sorios, and contains five articles on various aspects of analysis in this field. A third of the book is taken up with an article by Korkisch on ion exchange in mixed and non-aqueous media, which classifies separations partly by groups of elements and partly by eluant systems. The article is comprehensive, but it is so arranged that exten- 